Canadian University Music Review

Canadian University Music Review

Revue de musique des universités canadiennes

\title{
Wolf Music: Style, Context, and Authenticity in R. Murray Schafer's And Wolf Shall Inherit the Moon
}

\section{Ellen Waterman}

Volume 18, numéro 2, 1998

URI : https://id.erudit.org/iderudit/1014655ar

DOI : https://doi.org/10.7202/1014655ar

Aller au sommaire du numéro

Éditeur(s)

Canadian University Music Society / Société de musique des universités canadiennes

ISSN

0710-0353 (imprimé)

2291-2436 (numérique)

Découvrir la revue

Citer cet article

Waterman, E. (1998). Wolf Music: Style, Context, and Authenticity in R. Murray Schafer's And Wolf Shall Inherit the Moon. Canadian University Music Review / Revue de musique des universités canadiennes, 18(2), 72-88.

https://doi.org/10.7202/1014655ar
Résumé de l'article

R. Murray Schafer's environmental music functions as a model for his ideal of an authentic Canadian musical identity. Schafer's idea of the North is embodied both in the music's style and in its context. Three works from the music drama Patria the Epilogue: And Wolf Shall Inherit the Moon serve as examples of the influence of the northern soundscape on Schafer's musical style.
All Rights Reserved @ Canadian University Music Society / Société de musique des universités canadiennes, 1998
Ce document est protégé par la loi sur le droit d'auteur. L'utilisation des services d'Érudit (y compris la reproduction) est assujettie à sa politique d'utilisation que vous pouvez consulter en ligne.

https://apropos.erudit.org/fr/usagers/politique-dutilisation/ 


\section{WOLF MUSIC: STYLE, CONTEXT, AND AUTHENTICITY IN R. MURRAY SCHAFER'S AND WOLF SHALL INHERIT THE MOON}

\section{Ellen Waterman}

R. Murray Schafer has spent much of the latter part of his career developing and refining a style of music designed specifically for performance in the Canadian wilderness. ${ }^{1}$ Functioning in a ritual/theatrical context, such music constitutes a model of Schafer's well-documented ideas about Canadian culture. ${ }^{2}$ This article will examine Schafer's environmental music through three works from Patria the Epilogue: And Wolf Shall Inherit the Moon. They are the Aubade and Nocturne for solo clarinet (1993), Sun Father/Earth Mother for solo soprano (1984, revised 1991), and Tapio for alphorn with echoing instruments (1992). ${ }^{3}$ I will argue that in his music for And Wolf Shall Inherit the Moon, and in accordance with his theory of the Theatre of Confluence, Schafer is seeking a transformative integration with the northern wilderness soundscape that resonates with his ideal of "authentic" Canadian culture. 4

\section{Background}

And Wolf Shall Inherit the Moon is the ambitious epilogue to R. Murray Schafer's magnum opus, the cycle of twelve musical/theatrical works called Patria (1966-). Known colloquially as the Wolf Project, it takes the form of a week-long ritualistic music drama performed each August in the wilderness of the Haliburton Forest and Wild Life Reserve located in central Ontario, near Algonquin Park. And Wolf Shall Inherit the Moon was begun in 1988 and is an on-going project whose participants are simultaneously creators, performers, and audience. 5

1 This paper was originally presented at the 1997 conference of the Canadian University Music Society in St. John's, Newfoundland, where it was co-winner of the George Proctor prize. All musical examples are used with the kind permission of R. Murray Schafer.

2 See for instance R. Murray Schafer on Canadian Music (Bancroft, Ont.: Arcana Editions, 1984) and Patria and the Theatre of Confluence (Indian River, Ont.: Arcana Editions, 1991).

3 These works and others from And Wolf Shall Inherit the Moon have been published under the title Wolf Music (Indian River, Ont.: Arcana Editions, 1997).

4 Integration is used here in the Jungian sense of uniting the separate parts of the psyche to form a harmonious whole. For a full treatment of the Jungian influences on Patria, see Kirk MacKenzie, "A Twentieth-Century Musical/Theatrical Cycle: R. Murray Schafer's Patria" (Ph.D. diss., University of Cincinnati, 1991).

5Schafer wrote a "First Sketch" of And Wolf Shall Inherit the Moon in 1985, but did not act on producing the piece until he advertised for volunteer participants during the 1988 production of Patria 3: The Greatest Show in Peterborough, Ontario. The project began with five participants and has grown 
The complete work calls for 64 adult participants, divided into eight clans, at four campsites on different lakes in the northern end of the reserve, where there are no dwellings or roads. Each clan has its own part to play. Throughout the week, the clans will visit one another, but it is only on the final day that they all [come together] to enact the finale which is both ritualistic and dramatic. ${ }^{6}$

The mythopoeic theme of And Wolf Shall Inherit the Moon is the unification and transfiguration of its protagonists, Wolf and the Princess of the Stars. They are masculine and feminine archetypes whose heroic journeys of self-discovery are recorded throughout the Patria series. For the epilogue to Patria, Schafer has created music that parallels his literary theme: music that is inextricably linked to, and transformed by, the context in which it is to be performed.

Before considering Schafer's music for And Wolf Shall Inherit the Moon, however, it is necessary to understand the theme story on which the work is based. ${ }^{7}$ The story opens on a world fractured by the greed and hubris of the humans, who have abandoned their place in the Great Wheel of Life. ${ }^{8}$ Similarly, Wolf, a grim and lonely brute, is a symbol of alienation from nature. His anger isolates him from all other creatures: "Each night you could hear him howling and his howling struck fear in humans and animals alike." 9 The Princess of the Stars, who is signified by soprano vocal music, symbolizes the saving grace of compassion. ${ }^{10}$ She is victimized by Wolf's brutishness:

The Princess of the Stars heard Wolf's mournful cry. Pitying him, she fell from the sky to the earth. She hoped to reconcile Wolf with the other animals, but Wolf, in his rage, lashed out with sharp teeth and wounded the Princess. She fled to a lake. There, while she was washing her wounds, Three-Horned Enemy rose up, captured the Princess and pulled her down into the water. Three-horned Enemy imprisoned the Princess. ${ }^{11}$

Fortunately, the dawn birds saw the Princess's dilemma and alerted Sun Father, who descended to earth. He caused the Three-Horned Enemy to release the Princess's jewelled crown to the sky, but ordered her to remain on earth until she could tame Wolf with her compassion. As for Wolf, he was condemned to wander the earth until he could find the Princess. Only when they were re-united would harmony be restored.

to over seventy-five members including adults and children.

6Schafer, "Information for Prospective Members," "Ninth Draft" of Patria the Epilogue: And Wolf Shall Inherit the Moon, 1997.

7 Schafer originally wrote the theme story for Patria the Prologue: The Princess of the Stars, which is the companion piece for And Wolf Shall Inherit the Moon.

8 The wheel as a symbol of unity in nature can be found in many cultures, including the First Nations' medicine wheel, the Chinese concept of yin/yang, and Jung's double quaternity. The Great Wheel of Life borrows from all of these concepts.

9Schafer, "Ninth Draft" of And Wolf Shall Inherit the Moon, 8.

10In fact, in The Princess of the Stars, while Wolf, Sun Father (called Sun Disc), and the Three-Horned Enemy are represented by huge puppets, the Princess is never seen. She is known only by her haunting solo vocal arias.

11 Schafer, "Ninth Draft" of And Wolf Shall Inherit the Moon, 8. 
Wolf has been wandering for centuries, sometimes in the form of a man. $\mathrm{He}$ and [the Princess] have often met, but they've always parted. Re-union was not possible. The land was tainted and the people unprepared. ${ }^{12}$

And Wolf Shall Inherit the Moon concerns the efforts of the earth's creatures to restore harmony in nature by creating a ritual whereby Wolf and the Princess of the Stars may be united. If the ritual is successful, Wolf and the Princess will be released from their earthly bondage. The Princess will regain her crown and Wolf shall inherit the moon, becoming its deity. When balance is restored the human clan will be rejuvenated in the Great Wheel of Life. Metaphorically speaking, Schafer provides a model in which transformation results from the marriage of nature and art-a model that is closely connected to his ideas about Canadian culture. ${ }^{13}$

The Wolf Project is more than a work of art; it is the apotheosis of Schafer's theory of art, called the Theatre of Confluence. Outlined in two essays published in Patria and the Theatre of Confluence (Indian River, Ont.: Arcana Editions, 1991), Schafer's theory advocates a wilderness setting, a ritualistic and synaesthetic form, a collaborative process, and an emphasis on provoking existential change in its participants.

This must be the first purpose of art. To affect [sic] a change in our existential condition. This is the first purpose. To change us. It is a noble aim, a divine aim. And it existed long before the stale word "art" was coined to describe the last tremor of this transformative power accessible to civilized man. ${ }^{14}$

The Theatre of Confluence, then, wants to do far more than entertain a passive audience. Its transformational goal necessitates the active participation of everyone involved. Schafer calls his ritualistic and participatory music dramas "hierophanies" (a Greek term meaning the exposition of sacred mysteries) to express his search for an artistic form dedicated to a recovery of the sacred. Significantly, for Schafer, such a form may best be discovered outside of the traditional venues for art.

To accomplish an art that engages all forms of perception, we need not only to strip down the walls of our theatres and recording studios, but also the walls of our senses. We need to breathe clean air again; we need to touch the mysteries of the world in the little places and the great wide places; in sunrises, forests, mountains and caves ... For too long the clement temperatures of our theatres have neutralized our thermic sensibilities. ${ }^{15}$

12 Ibid.

13 See my Ph.D. dissertation, "R. Murray Schafer's Environmental Music Theatre: A Documentation and Analysis of Patria the Epilogue: And Wolf Shall Inherit the Moon" (University of California, San Diego, 1997). I have shown that And Wolf Shall Inherit the Moon operates on multiple levels (literary, theatrical, and methodological as well as musical) as an allegory of Schafer's ideas about Canadian culture.

14Schafer, "Patria and the Theatre of Confluence II," in Patria and the Theatre of Confluence, 87. 15 Ibid., 97-98. 
Thus the Theatre of Confluence aims for a transformative integration with nature. As Schafer explains, "we will not try to change things here; we will let them change us." 16

The Wolf Project emulates the Theatre of Confluence in a number of ways. Its members include musicians, artists, dancers, and actors from both the professional and amateur spheres. Because of its rugged location, camping and canoeing skills are as important to the piece as artistic ability. Thus Schafer works towards breaking down the bifurcations of consumer/creator, amateur/professional, audience/performer, and nature/culture. Every aspect of And Wolf Shall Inherit the Moon is affected by its ritualistic form, its cultural specificity and, above all, by its romantically idealized wilderness context. ${ }^{17}$ The composer listens and writes differently, his music transmogrified by rock, echo, lake, and mist. As a musician who has participated in the Wolf Project since 1990, my experience has been that the performer is also transformed. The northern wilderness soundscape engages the performer in an intense and intimate dialogue with nature.

\section{Style and Context}

To date, Schafer has written twenty-two compositions for And Wolf Shall Inherit the Moon, encompassing ensembles as well as a significant body of solo instrumental and vocal works. ${ }^{18}$ While Schafer's music is a strong unifying force in And Wolf Shall Inherit the Moon, it is only one aspect of music in the Wolf Project, which also features choral and instrumental works written by other project members. The examples discussed below represent three distinct genres of music used in And Wolf Shall Inherit the Moon: ritual solos, theatrical arias, and incidental ensembles. Together they will show how Schafer has developed a style suited to the wilderness environment, as well as ways in which the environmental performance context transforms the music itself.

One is apt to speak of "environmental" music (by which I mean music designed to be played outside of the controlled acoustics of the concert hall) as if it was one thing. Schafer's Wolf Music is written specifically for a wilderness environment in which field, lake, forest, and rock yield quite different responses to sound. Thus the art of playing in the wilderness consists of an acute sensitivity to the particular performance space and time. Bird calls differ at dawn and at dusk. Then too, the wind tends to be calm at those times but rises in the middle of the day to whip a melodic line to rags. Rain dampens sound; however, to play across a lake at dawn is to play into mist, which has

16Ibid., 98.

17One could argue that the privately owned Haliburton Forest hardly epitomizes rugged northern wilderness. More significant is the mythic ideal of the wilderness embodied in the themes of And Wolf Shall Inherit the Moon. That said, it certainly feels like "real" wilderness, given the incredible logistics of mounting a week-long drama in the forest. Certainly, it contains all the necessary ingredients for Schafer's wilderness music to succeed.

18 And Wolf Shall Inherit the Moon is very much a work in progress. Most of the music has been written for voice, trumpet, flute, clarinet, oboe, trombone, recorder, and alphorn. These choices reflect the talents currently available in the project and could change as different instrumentalists join. 
an extraordinary power to carry sound. As Schafer is fond of saying, every performance in the wilderness theatre is a premiere.

\section{Aubade and Nocturne for Solo Clarinet}

About half of Schafer's works for And Wolf Shall Inherit the Moon are short solos called Aubades and Nocturnes. They are meant to be heard at dawn and at night, from deep within the forest or across a lake, framing each day at the Wolf Project with music. Written over many years for specific musicians in the project, they are short and idiomatic.

The form common to all the Aubades and Nocturnes dates back to the composer's early studies of troubadour songs, in which small motives were combined and expanded in various ways. ${ }^{19}$ The principal melodic motif is introduced near the beginning, with perhaps three or four other motivic ideas presented in a discursive relationship with one another throughout the course of the piece. A narrative flow results "emblematic of a statement which is then buried or contradicted but that is closer to speech and language than some other kinds of music." 20 Schafer's Aubades and Nocturnes are, in fact, songs without words.

Within these economic means, Schafer has created a subtle and organic form that complements the function of the Aubades and Nocturnes. As Schafer explains in his notes to the score:

One of the rituals of the Wolf Project is to frame each day with an Aubade and a Nocturne, usually played or sung by a soloist from across a lake. The Aubade is our wakeup call and the Nocturne closes the campfire each night. The rule of the camps ... is that the day begins silently without talking; similarly, when the Nocturne begins at night, silence is observed. The idea is that the Nocturne should extend into the soundscape of the night without further human comment. Often I have heard what I could only call the "phantom sound" of the Nocturne continuing long after it is over, blended with the crickets, water and night birds of the forest.

Such an effect would be impossible in a concert hall. The pieces included here probably don't belong there at all. I publish them only to make them available to a wider circle of performers who may appreciate the spirit in which they were written and the environment in which they should be performed. ${ }^{21}$

Indeed, a fully realized interpretation of the Aubades and Nocturnes would necessitate performing the works at their appropriate times and in their proper settings, much in the way that certain Indian ragas are defined by extra-musical conditions of time, place and season. ${ }^{22}$

19 Schafer, interview with the author, 17 October 1996.

20 Ibid.

21 Schafer, notes to the score of Wolf Music (Indian River, Ont.: Arcana Editions, 1996), 1.

22Some musicians in the Wolf Project (including the author) have played the Aubades and Nocturnes in concert settings. While the works seem musically satisfying to audiences, they are written so specifically for the interplay of time and place that a concert performance falls inevitably into the realm of imitation. Schafer's concerto, The Falcon's Trumpet (1995), is closely related to his Nocturne for solo trumpet. It is an interesting example of the composer's own attempt to transpose his environmental music style into the concert hall. 
Taken together, the Aubade and Nocturne for solo clarinet are paradigmatic examples of Schafer's use of a narrative form that is intimately linked to a specific performance context. The two pieces are closely connected, sharing motivic material that is manipulated in such a way as to emphasize the ritual function of the works: celebrating the rise and fall of the sun.

Schafer states that his approach to the composition of these works begins with the discovery of a characteristic motif. ${ }^{23}$ In the clarinet pieces it takes two forms, as example 1 shows. Through most of the Aubade, the motif is a downward leap of a minor third followed by an appoggiatura leap upward by a major third. The first appearance of the motif is in the low register and it gradually rises with each successive reiteration. At the end of the piece the motif, now in the high register, is modified so that both the downward and the upward leaps are by a major third. This latter form of the motif is heard throughout the Nocturne.

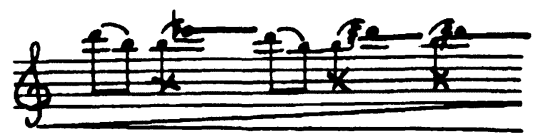

Minor/major form line 19: Aubade

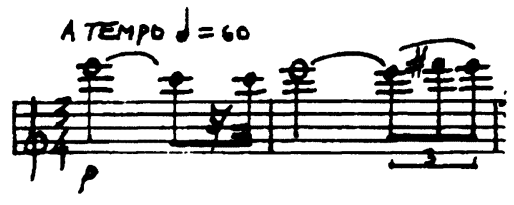

Major form

line 9: Nocturne

Example 1: Aubade and Nocturne for solo clarinet, characteristic motif

The sense of a narrative structure is reinforced by the similar tonal language of both pieces, and the manner in which the motif is embedded in that language. Both works contain chromatic series of trills (both half and whole note), arpeggiated seventh and ninth chords, scale passages (in intricate patterns of half tones, whole tones, and minor thirds), and chains of tritones and perfect fourths.

The Aubade opens with three series of ascending D-sharp minor-seventh chords in the chalumeau register, each followed by a short improvisation on the same chord, "like mist over water." 24 Given the pre-dawn performance context in which the clarinettist plays beside a lake, it seems probable that Schafer is thinking of the thick cloak of mist which frequently covers the Haliburton lakes before dawn, only to burn off as the sun gains strength. As example 2 shows, the first of many ascending groups of trills bubbles up from the chalumeau register, followed by the entrance of the characteristic motif. Following the work's narrativity, I will call it the "sun motif" because its

23 Schafer, interview with the author, 17 October 1996.

24The Aubade and Nocturne for solo clarinet are transposed. For clarity, my analysis refers to the written, not the sounding, pitch. For example, the D-sharp minor chords of the opening would sound as $\mathrm{C}$-sharp minor chords when played. Phrases in quotation marks are score indications. 
leaping thirds seem to evoke the first rays of the dawning sun piercing through the night chill. The sun motif builds in strength throughout the Aubade, rising in register with each occurrence out of ever more complex runs and arpeggiations linked by the ascending trill motif.

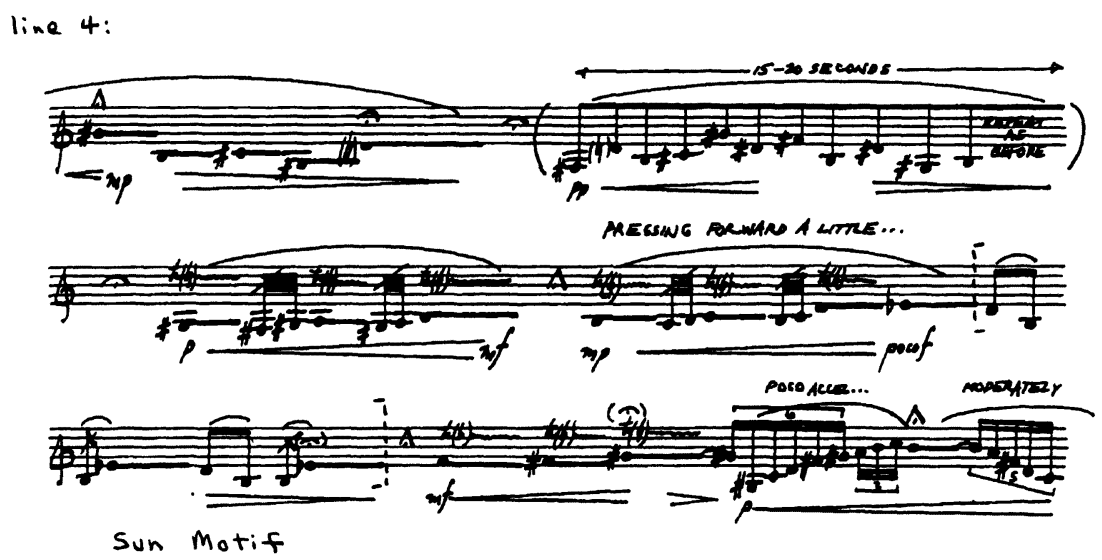

Example 2: Opening of Aubade for solo clarinet

About half-way through the Aubade a set of rhythmically accelerating chromatic runs culminates in a dramatic E-major arpeggio that rises over two and a half octaves. Repeated, this clarion call cadences in a four-note variation of the sun motif, shown in example 3: a rising major third (spelled as a diminished fourth), a descending major sixth, and a rising minor third.

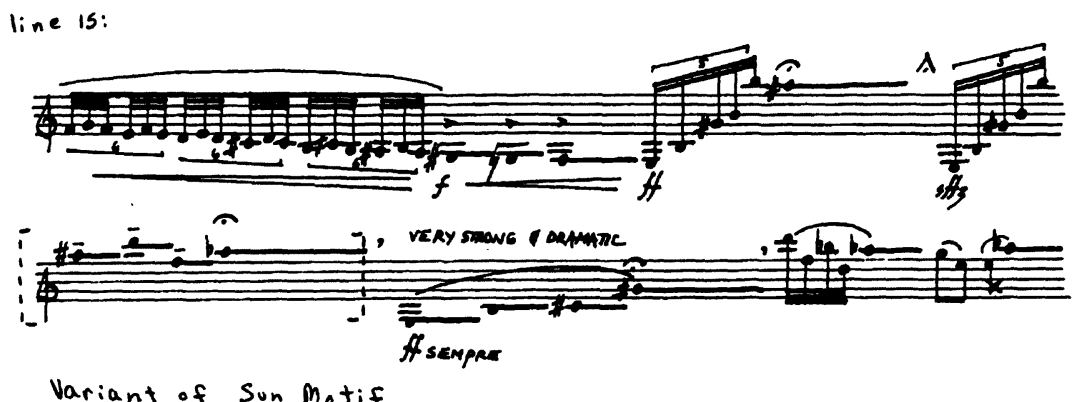

Example 3: Aubade for solo clarinet, variant of the sun motif

This variant of the sun motif is followed by a recurrence of the sustained opening passages (transposed down a whole tone), but instead of being marked "slow and peaceful" they are now marked "very strong and dramatic." Dispensing with all suggestions of "mist over water," the line rises to the last (and highest) reiteration of the sun motif in its minor/major form. After a pause, the last third of the piece (marked "starting deliberately; accelerando...") rushes 
headlong towards the end in a cascade of chromaticism. The trill motif is heard once more, and a long run ascends to a high-note motif, seen in example 4. It consists of four even notes beginning with an upward leap of a major third followed by two descending leaps (an augmented second and a tritone).

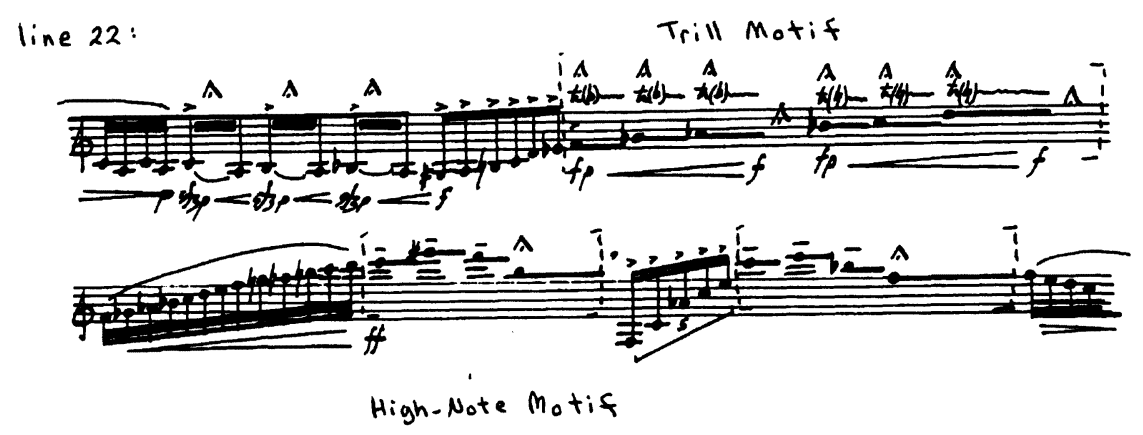

Example 4: Aubade for solo clarinet, high-note motif

In keeping with the discursive relationship of Schafer's motivic material, the high-note motif is related to both the sun motif and its variant. Rhythmically, the high-note motif imitates the four even quarter notes seen in the variant of the sun motif (example 3). Clearly, it inverts the sun motif's downward leap of a minor third and upward leap of a major third with its upward leap of a major third and downward leap of a minor third (spelled as an augmented second). This inversion marks a turning point: hereafter, the sun motif is always presented in its brighter, major-third form. As shown in example 5, the Aubade concludes with four lines of the altered sun motif in the clarino register "gradually receding into the dawn soundscape" as though the sun has triumphantly risen, and burned through the mist, as indeed, in the ideal performance context, it has.

The shorter Nocturne takes up precisely where the Aubade leaves off, sounding the sun motif on $\mathrm{E}^{6}$ and $\mathrm{C}^{6}$ as seen in example 6 . The melody then descends through a series of triadic and seventh-chord arpeggios (C augmented, $\mathrm{C}$ minor, D half-diminished seventh, E diminished seventh, E minor, and $\mathrm{B}$ minor) to the trill motif, which, in the Nocturne, is always descending.

The Nocturne is in three sections, each beginning with the sun motif. The first two reiterate the same $\mathrm{C}$ augmented and $\mathrm{C}$ minor arpeggios. Remembering the narrative structure and ritual context of the two works, the general shape of arpeggiation in the Aubade can be seen as that of a hill, as if to symbolize the rise and fall of the sun throughout the day. By contrast, in the Nocturne, arpeggios always descend into a valley and ascend out of it, as if to symbolize the journey of the sun through the underworld before it can again ascend to the sky (a theme Schafer explored in Patria 6: $R A$ ). The third section is preceded by a reiteration of the same high-note motif that signalled the end of the Aubade. In the last two lines of the piece, the sun motif traverses deep valleys of C-major-ninth arpeggios. The last reiteration of the sun motif, seen in 

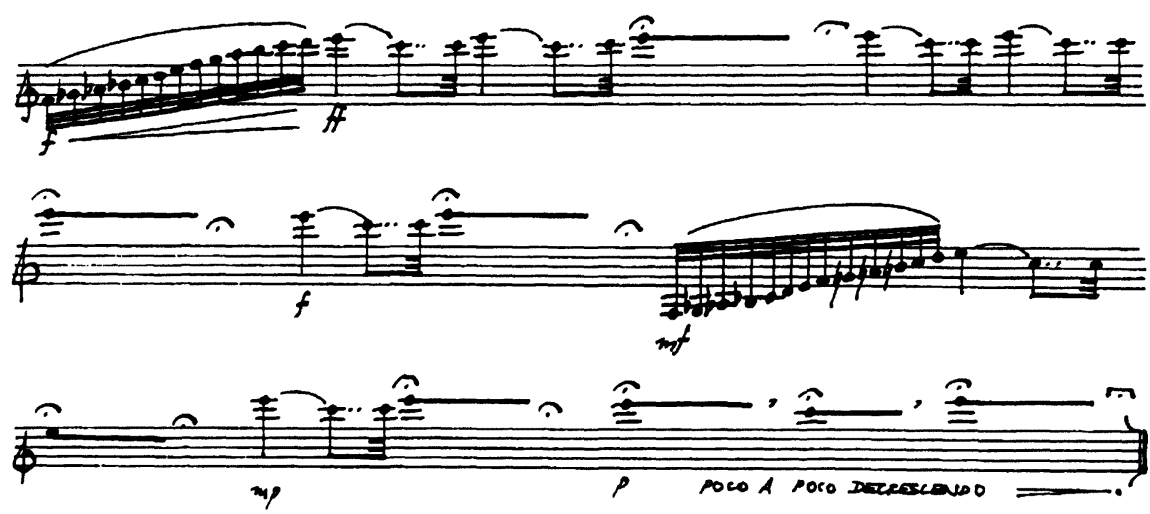

TME LAST THEE NOTES MAY IE RETEATRD AD 48, GRAPUALY RECEDING INTO THE DNWW SOCWDSCADE .

Example 5: Ending of Aubade for solo clarinet

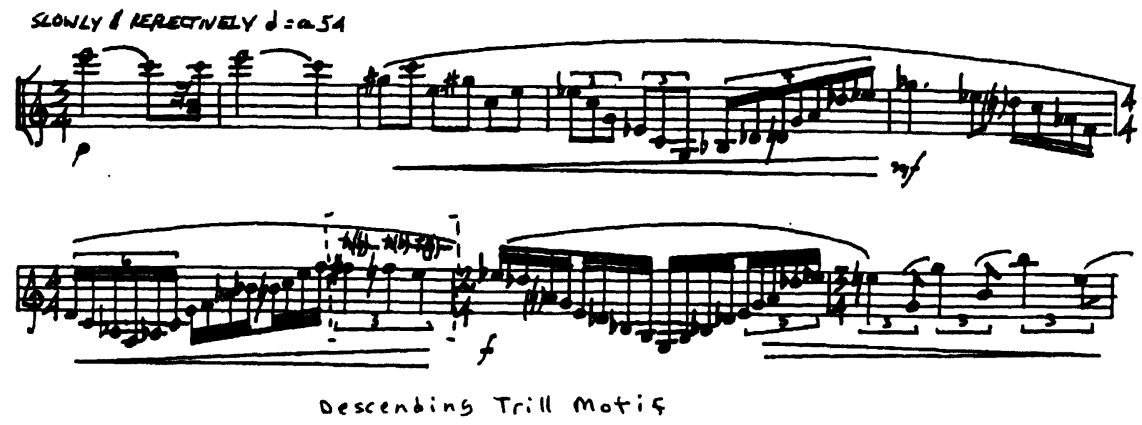

Example 6: Opening of Nocturne for solo clarinet

example 7 , is presented in a slow $3 / 4$ metre without the appoggiatura. The final four notes outline a "drawn out" descending triad in C major that comes to rest on the dominant, perhaps to signify that the loss of the sun is only temporary.

The metaphor of a "sun motif" is an appropriate way to think about two pieces which are designed to frame the day. It is suggested by Schafer's indication to the clarinettist to play "like mist over water" at the beginning of the Aubade, and reinforced by the continuously rising shape of the piece, in which the first instance of the sun motif is in the husky chalumeau register and the last reiteration is at the ringing top of the clarino register. The fact that the Nocturne begins with the same high material (to be played "slowly and reflectively") provides a thematic link that emphasizes the ritualistic function of the two pieces. Reflecting the cyclical nature of the performance context, the Nocturne mirrors the Aubade with its descending trills, its valley arpeggios, and its meditative ending. 


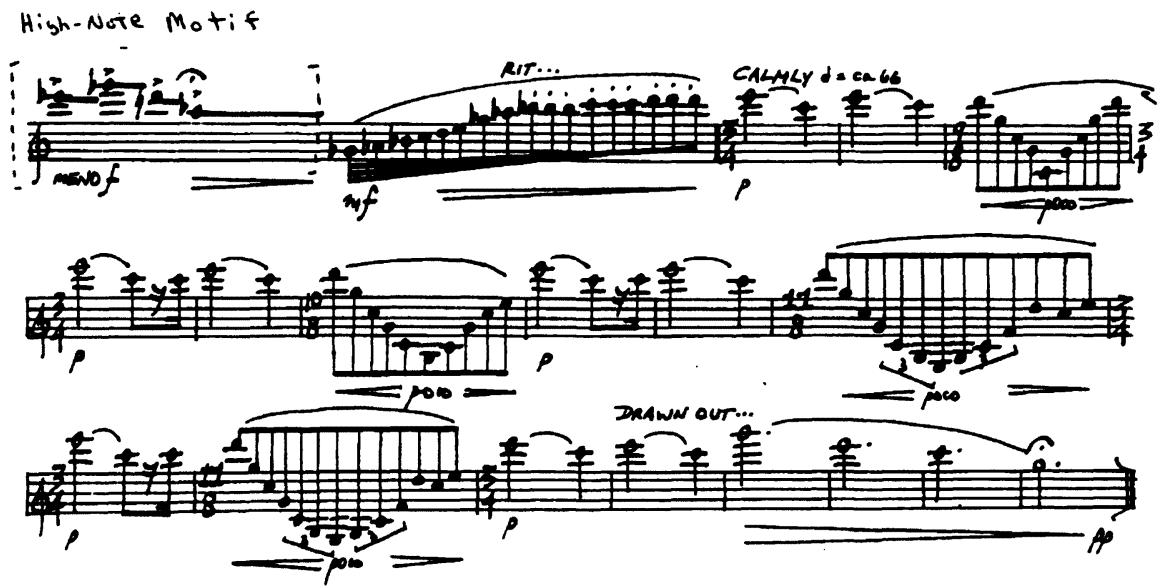

Example 7: Ending of Nocturne for solo clarinet

\section{Sun Father/Earth Mother for Solo Voice}

And Wolf Shall Inherit the Moon culminates in a day-long pageant in which the clans join together in order to enact a ritual to attract Wolf and the Princess of the Stars into the Great Wheel of Life. Symbolic of unity and harmony, the wheel is also a literal stage in which theatrical events occur. The Great Wheel is a large area in a meadow demarcated by natural objects such as dead trees and stones. It is approximately twenty feet in diameter, and is divided according to the cardinal and intermediate points on the compass, so that each clan has its own place within the wheel. This wilderness "set" also encompasses the perimeter of the nearby forest, a high rocky area and a river.

The Princess of the Stars is the principal vocal soloist in the Great Wheel Day. It is an appropriate role since "the thread-gift" of her "haunting voice ... sustains and transforms [Wolf] during his life journeying." 25 As the Princess of the Stars enters the Great Wheel, she sings several sections of the aria Sun Father/Earth Mother, which Schafer first wrote for the soprano Eleanor James in 1984 and then revised for And Wolf Shall Inherit the Moon in $1991 .{ }^{26}$ The Princess begins singing the aria up on Moose Rock and continues as she travels several hundred yards to the entrance of the Great Wheel of Life.

Sun Father/Earth Mother is a good example of Schafer's attempt to achieve a transformative integration with nature, both with his characters and in their music. The Princess travels to the Great Wheel in order to effect the transformation of herself and Wolf that will restore harmony to all nature, and the agent of that transformation is her voice. As Schafer states, "in Sun Father/Earth

\footnotetext{
25Schafer, "Patria the Prologue: The Princess of the Stars," in Patria and the Theatre of Confluence, 107.

26In 1997 Schafer wrote an orchestral accompaniment to the vocal music which this analysis predates. It consists largely of supporting harmonies and parallel melodies, and does not affect the vocal line substantially. The songs are published in Wolf Music as a solo work.
} 
Mother the singer invokes the whole of nature by singing to each of the elements in turn." 27

The work is through-composed in ten verses celebrating different aspects of nature: "Sun Father," "Earth Mother," "Moon," "Stars," "Mountains," "Birds," "Fish," "Forests," "Animals," and "Spirits." Each verse begins by addressing the subject and extolling its qualities. They are unified by the Princess's relationship to each subject: "I come to you, I sing to you, ... I am one with you," always sung on a wide leap up to a sustained note. Example 8 illustrates this usage in the second verse, Earth Mother. Schafer notes that, "in a suitable environment the phrase 'I come to you, I sing to you' will fuse the solo voice with the echo so that it is impossible to identify the source of the sound - the human is blended totally with the environment." 28

line 8:

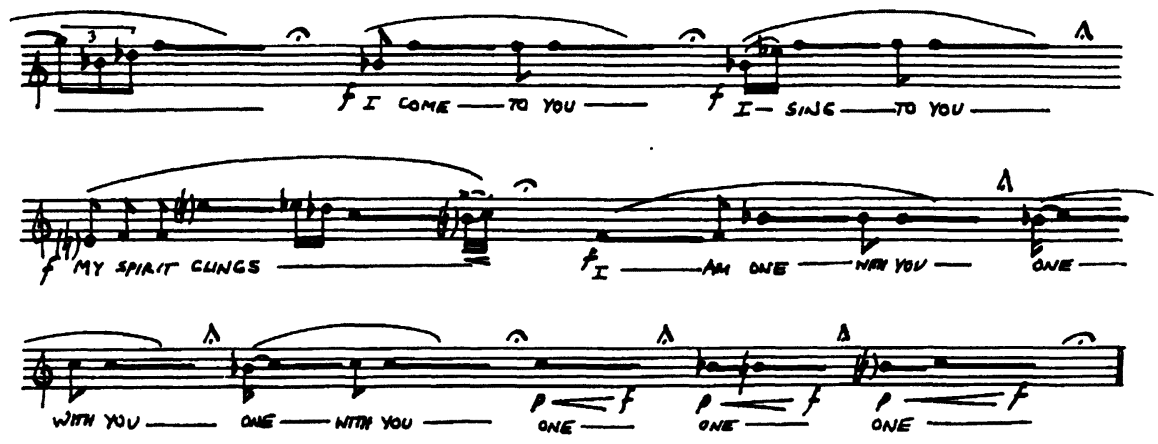

Example 8: Earth Mother

The chief stylistic device in Sun Father/Earth Mother is the vivid word painting through which Schafer illustrates the natural subject matter of each verse. As table 1 illustrates, a particular affect is attached to each subject and expressed mimetically in the music. For instance, the spirit "clings" to Earth Mother with a sighing melodic phrase. In contrast, the spirit "grows" with the forest through an extended series of chromatic runs, while it literally "howls" to the animals.

As the subject matter of Sun Father/Earth Mother suggests, Schafer's wilderness music welcomes, and indeed emulates, the natural sounds of the environment. Accordingly, almost all of his solo wilderness works are unmetred or have "free" sections allowing the performer to set the pace according to the immediate responsiveness of the particular performance 
Table 1: Word Painting in Sun Father/Earth Mother

Verse "My spirit ..." Word Painting

Sun Father soars

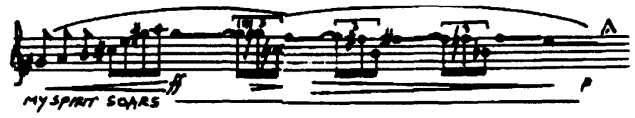

Earth Mother clings

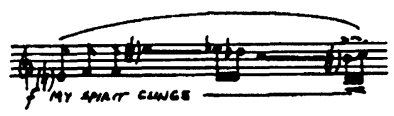

Moon

yearns

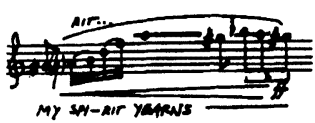

Stars

rises

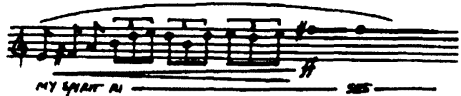

Mountains arches

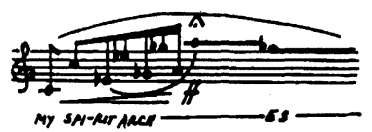

Birds

flies

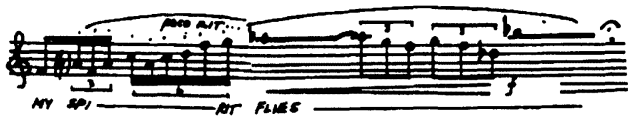

Fish

swims

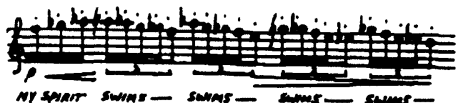

Forest

grows

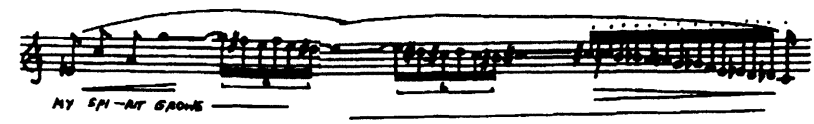

Animals howls

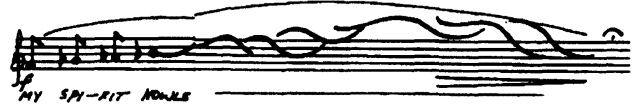

space. As example 9 shows, Sun Father features swooping portamento leaps followed by pauses, a device which, under the right circumstances, triggers multiple echoes like a smooth rock skipping across a lake. Thus, at one and the same time, the singer expresses the qualities of the environment and provokes its response. 


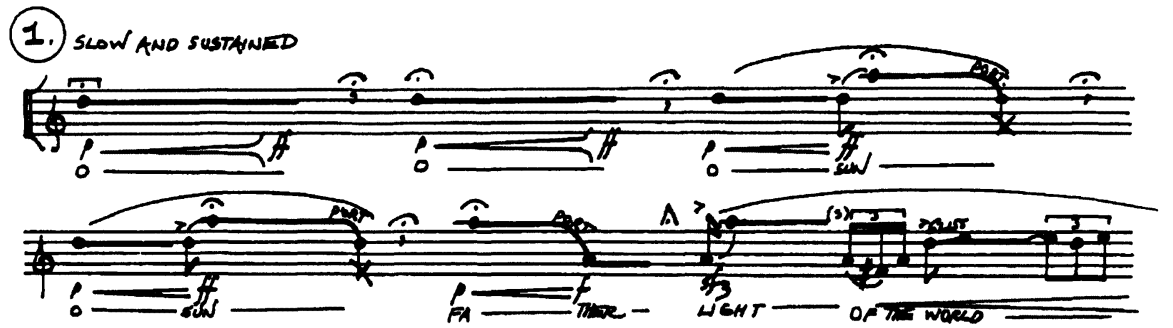

Example 9: Sun Father

\section{Tapio for Alphorn and Echoing Instruments}

Schafer's ensemble music for And Wolf Shall Inherit the Moon often plays with the dual phenomena of natural and artificial echoes. Listening to this call and response, the ear becomes uncertain of the origins of sound. Do the musicians "play the environment" or is it the very forest that sings? For instance, Tapio is a triadic work for alphorn and echoing instruments that functions as a processional for the pageant known as the Great Wheel Day. An apparently simple piece, it is a dramatic example of Schafer's use of echoes as a structural and stylistic device in order to achieve the integration of the music with the surrounding soundscape.

Example 10 shows a fragment of the alphorn part for Tapio. Various accompanying instruments, such as recorder, oboe, flute, clarinet, trombone, and trumpet also have this music. Each performer listens for the alphorn to initiate a phrase and then chooses small fragments of that phrase to play as an echo. For the most part the decision of what and when to play is left up to the performers, who respond both to the alphorn and to each other. Over a number of years of playing the work, Schafer's performers have developed an informal agreement on density, in which the upper winds echo the busier passages, while the lower brasses echo pedal tones and slower phrases.

Tapio's echo structure presents some interesting performance problems. In the theatrical performance context, the players are widely separated, perhaps fifty feet apart, hidden from the audience and from each other. It is very difficult for the musicians to hear one another given both the distances and the wide variety of possible weather conditions, including wind and rain. Then, too, pitch is profoundly affected by the environment. It is impossible for an ensemble of instruments to play "in tune" in the wilderness. Either it is cold and someone is irretrievably flat, or it is damp and a reed refuses to function properly. Pitch problems are exacerbated by the fact that the alphorn utilizes natural tuning. Tapio exploits the seventh and eleventh partials which are 31 cents and 49 cents flat, respectively, when compared with the equal-tempered B-flat and G-flat of the echoing orchestral instruments. Further aural confusion results from the remarkably accurate and consistent pitch of the natural echoes. Oddly enough, fluctuations of intonation that would immediately irritate a 


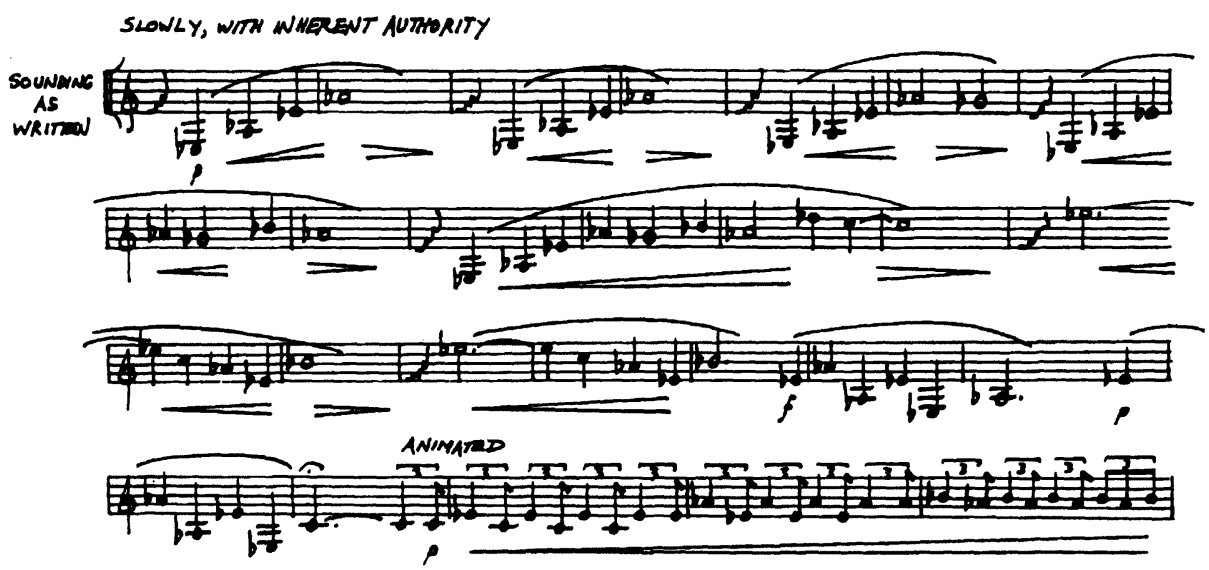

Example 10: Tapio

listener in the concert hall become diffused and less important outdoors. Sound carries over vast distances, bent by the wind, and echoing instruments occupy individual timbral/pitch territories, creating a heterophonic interplay of similar, but not exact, echoes.

The natural resonance of the wilderness environment produces complex aural illusions. The soprano becomes a chorus of loons; the clarinet assumes the multiple resonances of an organ; the brassiness of the trumpet is magically silvered; and the flute provokes a chorus of songbirds. The wilderness creates its own dynamic, and Schafer insists that it is this dynamic that makes the music distinctive.

The important thing about the Wolf Project is that it's a total change of context. You can't lose that. You can't say "the style of this is very conventional when compared with what's happened in 20th century music." I can only reply, "who else has gone into the wilderness and tried to make music?"29

\section{Authenticity}

Before he began to write music for the wilderness environment in the late 1970 s, Schafer wrote a poetic manifesto called Music in the Cold in which he imagined the effect of the northern environment on Canadian music:

The snows came early this year.

It is the beginning of a new ice age.

The wind howls at our ears as we dig for wood in the snow, and I wonder

what this will do for music?

It'll toughen it up.

29 Schafer, interview with the author, 17 October 1996. Of course, Schafer is not unique in moving music into a wilderness environment, but he is an undisputed pioneer in the practice of environmental music and the study of environmental sound: see his The Tuning of the World (Toronto: McClelland and Stewart, 1977). 
It'll reduce it to the lean shape, maybe even bare bones.

And its form will become clear as an icicle. ${ }^{30}$

Anyone who examines Schafer's environmental compositions is immediately aware of the sinuous, dark, and even voluptuous lines, the plummy half-diminished seventh chords, the cascading triplets, and wild trill sequences. This is music that twists and twines, labyrinthine and mysterious, always giving the impression of an elusive, constantly shifting tonal centre. This is music that runs scrolloping over the page like the elaborate ink drawings with which Schafer illuminates his scores. Yet, writes Schafer, "the art of the north is the art of restraint." 31

Schafer freely admits that his disposition is far too romantic to permit such austerity in his compositional style. ${ }^{32}$ Nevertheless, the idealized northern wilderness has had a profound effect on his music. After all, Schafer believes that the great revolutions in music have been not those of style, but those of context. In his second essay on the Theatre of Confluence, the composer states that:

Modern theory teaches that revolutions in art occur when styles are challenged. But they ignore the bigger revolutions of context change. Styles vary constantly but it often takes centuries before an artistic tradition, locked into one environment is released to find another. ${ }^{33}$

For example, Schafer cites the movement of music into the Church in the Middle Ages, and the subsequent shift from Church to theatre which occurred in the seventeenth and eighteenth centuries. Significantly, it is the context of being performed in the wild that strips the music. As Schafer admits:

When I hear solo instruments, or the few instruments that we have [in the Wolf Project] playing outside—or any of the singing we do-in that enormous space, it seems so exposed and so fragile. In that sense the relationship of the environment to the music influences the music, whether you want it to be influenced or not. ${ }^{34}$

This influence consists, in part, of Schafer's deliberate simplification of materials when writing environmental music. For instance, dynamic variations are lost when performed outdoors. Music is either coming towards the listener and is thus louder, or receding and is thus softer. The same is true of the delicate shaping of a note or subtle shades of timbre; they do not "read" well out of doors. In this sense, the music is certainly lean, relying on mellifluous line rather than timbral or harmonic complexity. ${ }^{35}$

30Schafer, Music in the Cold (1977), reprinted in R. Murray Schafer on Canadian Music, 64. The composer and his wife had recently moved from the urban and temperate climate of Vancouver to an old log cabin outside Bancroft, Ontario. Perhaps prepared by his researches in the World Soundscape Project (see The Tuning of the World, 1977), this move marked a dramatic and permanent change in both Schafer's lifestyle and his music.

31 Ibid.

32Schafer, interview with the author, 17 October 1996.

33Schafer, "The Theatre of Confluence II," in Patria and the Theatre of Confluence, 96.

34Schafer, interview with the author, 17 October 1996.

35 This fact does not, however, prevent Schafer from writing such fine details into the music! 
Since writing Music in the Cold, Schafer has had twenty years of experience in composing environmental music, including such works as Music for Wilderness Lake (1979) and Patria the Prologue: The Princess of the Stars (1981). Indeed, it was with the writing of The Princess of the Stars that Schafer decided to root Patria in Canada. As he explains:

It was then that I conceived the idea that the whole cycle could start from our own treasure house of Canada. Then the characters could migrate, could wander the earth, more or less the way we all do in our time. As students we go to one or another country to get educated, to get acculturated in various ways. Ultimately, though, we come back to the same place where we were: enriched, changed, transformed but definitely we come back to the Canadian wilderness. ${ }^{36}$

Patria the Epilogue: And Wolf Shall Inherit the Moon, then, symbolizes the arrival home which is coincident with the maturity of Schafer's environmental music style. The circle was completed by the September 1997 performances of Patria the Prologue: The Princess of the Stars at Wildcat Lake in the Haliburton Forest - the exact location of the Wolf Project.

For Schafer, the integration between music and the environment is the key to developing an authentically Canadian musical identity. By "authentic" the composer means an identity that is derived from within the country, rather than imported from outside. In our increasingly pluralistic post-colonial society, Schafer still insists that the defining facts of Canada are its vast physical size and northern geography:

We shouldn't fool ourselves into thinking that's a crazy kind of myth, as many people do, because it is a physical reality. We have an enormous amount of space, and we can access the wilderness-real tough country that is uninhabited by human beings—quite easily in Canada. Few other parts of the world have that luxury anymore. ${ }^{37}$

By setting both the prologue and the epilogue to Patria in the Canadian wilderness, Schafer emphasizes the importance of environment to identity. $\mathrm{He}$ believes that the central problem in the development of an individuated Canadian culture is the alienation of Canadians from the vast northern wilderness that surrounds them. This alienation is seen in a population that hugs the southern border, imbibes popular culture imported from the south, and values foreign artistic products while, historically at least, scorning its own. Schafer has labeled such prejudice "colonial culture."

... that seems to be the most appropriate way to describe the insecurity which downgrades the local and elevates the alien without seriously evaluating either. This is a Canadian habit and, while it may be weakening in some areas, in the aristocratic field of classical music it is hardening into a canker. ${ }^{38}$

36Schafer, interview with the author, 19 June 1996.

37Ibid.

38 Schafer, "Canadian Culture: Colonial Culture," in R. Murray Schafer on Canadian Music, 88. 
Schafer's environmental compositions symbolize his attempts to redefine Canadian culture in terms of a wilderness that, while romantically idealized, is nonetheless real and accessible. It is a subject about which Schafer is passionate.

Our subject is Canadian culture. Both the adjective and the noun are emotional, and so they should be. They can't be objectified; they are under our fingernails, under our skin, fed by the heart. And yet, they are not, like our blood, a part of us, but are artificial concepts which someone else prepared for us to inhabit. I am a Canadian by accident; but I did not receive my birthright like a telephone number; I inherited with it a complex nucleus of habits and sensations that trigger mixed emotions. I love my country, but I despise it also. I love its natural beauty, but I weep for the destruction of it. I recognize the moulds that have shaped it but I agonize to reshape them. And I know that this is possible, even though I often wonder just what effect my efforts are having. ${ }^{39}$

In Patria, Schafer's will to "reshape" Canadian culture is paralleled by the heroic journeys of Wolf and the Princess of the Stars as they search for unity and identity. And Wolf Shall Inherit the Moon brings the theme to earth through the clans' ritual attempts to restore balance and harmony in nature. And in a very real way, the participants in the Wolf Project enact Schafer's cultural ideal by living and performing music in the Canadian wilderness.

Schafer's ideal of authentic Canadian culture may be summed up in the idea of the North which he feels is at the core of the Canadian identity. For Schafer,

The North is a place of austerity, of spaciousness and loneliness; the North is pure; the North is temptationless. These qualities are forged into the mind of the Northerner; his temperament is synonymous with them. ... The idea of North is a Canadian myth. Without a myth a nation dies. ${ }^{40}$

Patria is Latin for "homeland" and it is no accident that the music for And Wolf Shall Inherit the Moon has been written for, and drawn out of, the Canadian wilderness. The music of And Wolf Shall Inherit the Moon is rooted deeply in place, born of Schafer's idea of the North. In his Wolf Music Schafer has created a synthesis of style and context that is an eloquent expression of his cultural ideal.

\section{Abstract}

R. Murray Schafer's environmental music functions as a model for his ideal of an authentic Canadian musical identity. Schafer's idea of the North is embodied both in the music's style and in its context. Three works from the music drama Patria the Epilogue: And Wolf Shall Inherit the Moon serve as examples of the influence of the northern soundscape on Schafer's musical style.

39 Ibid., 76.

40 The program note to Schafer's orchestral piece North/White (1973), reprinted in R. Murray Schafer on Canadian Music, 63. 